\section{Cistinosis nefropática: caso clínico que ilustra diagnóstico molecular}

\author{
PAOLA KRALL ${ }^{1, \mathrm{a}}$, DANIELA NUALART ${ }^{1, \mathrm{~b}}$, JEAN GRANDY²
}

\section{Nephropatic cystinosis: report of one case}

Nephropatic cystinosis (NC) is a rare disease associated with pathogenic variants in the CTNS gene, with a common variant that consists of a 57kb-deletion involving CTNS. Patients with NC that are treated with cysteamine improve their life quality and expectancy. We report a 12-month-old girl with a poor growth rate since the $4^{\text {th }}$ month of life. She was admitted to the Hospital with acute kidney injury, severe dehydration and metabolic acidosis. She was treated with volume restorative and bicarbonate. Proximal tubulopathy and Fanconi's syndrome was diagnosed. Medical treatment improved renal function that was stabilized in stage 4 chronic kidney disease (CKD). Since infantile NC was suspected, CTNS genetic analysis was considered. Genomic DNA was isolated from peripheral blood to perform PCR for exons 3-12 in CTNS gene and for the specific $57 \mathrm{~kb}$-deletion PCR. Afterwards, variant segregation analysis was performed in the familiar trio. The genetic analysis showed that the patient was homozygous for the common 57kb-deletion encompassing CTNS that had been inherited from her asymptomatic heterozygous parents. The molecular confirmation allowed genetic counselling for parents and facilitated the access to cysteamine. Oral treatment with cysteamine resulted in improvement of renal function to CKD stage 3. After 16 months of treatment the patient shows metabolic stability and mild recovery of height. Ophthalmologic follow-up detected ocular cystine crystals 12 months after diagnosis, starting cysteamine drops.

(Rev Med Chile 2018; 146: 111-115)

Key words: Cystinosis; Cysteamine; Kidney Transplantation; Molecular Diagnostic Techniques.

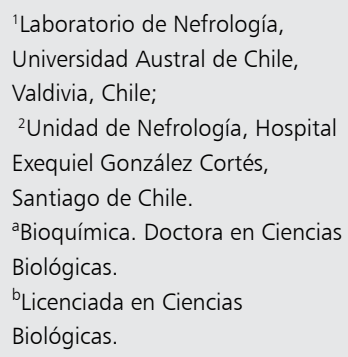

Los autores no declaran conflictos de interés.

Fuente de financiamiento: FONDECYT de Iniciación \#11140242.

Recibido el 18 de octubre de 2017, aceptado el 30 de enero de 2018.

Correspondencia a:

Dra. Paola Krall

Laboratorio de Nefrología, Universidad Austral de Chile, Coronel Bueras 1003, 2do piso, Hospital Base Valdivia, Valdivia, Chile. paolakrall@gmail.com

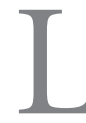

a cistinosis nefropática (CN;OMIM\#219800) es una enfermedad autosómica recesiva asociada a variantes patogénicas en el gen $C T$ NS(MIM\#606272), codificante para cistinosina, que funciona como proteína transportadora de cistina en los lisosomas ${ }^{1,2}$. Cuando la cistinosina es defectuosa, se acumula cistina que precipita en forma de cristales, lo que conduce a un deterioro progresivo de los órganos afectados. La frecuencia de la CN se estima en 1/100.000-200.000 nacidos vivos y su presentación clínica es de expresión variable, destacando los síntomas derivados de la tubulopatía con el síndrome de Fanconi ${ }^{3,4}$. El 95\% de los casos de CN se inicia antes de los 6 meses de vida, que constituye la forma más severa, dado que progresa a enfermedad renal crónica (ERC) terminal en la primera década 5 .

La CN tiene un manejo sintomático de la ERC y del síndrome de Fanconi, sin embargo, actualmente existe un tratamiento específico para reducir los niveles de cistina mediante el uso de cisteamina. Este medicamento fue creado en 1979 y permite la externalización de cisteína para evitar la acumulación intracelular de cistina ${ }^{6} \mathrm{El}$ uso precoz de cisteamina ha permitido prevenir significativamente la progresión del daño renal y el ingreso a diálisis, mejorando la expectativa de vida de los pacientes. En Chile no existen registros 
epidemiológicos sobre la frecuencia de $\mathrm{CN}$ en población pediátrica, solo existe el registro de un menor de 15 meses diagnosticado con $\mathrm{CN}$ mediante medición de concentración intracelular de cistina en leucocitos de sangre periférica, quien luego de 2 años de tratamiento con cisteamina mejoró su tasa de crecimiento y estabilizó su función renal, persistiendo la tubulopatía ${ }^{7}$.

\section{Espectro de variantes genéticas en CTNS asociadas a $C N$}

Se han descrito diversas variantes patogénicas en el gen CTNS, que predicen sustituciones aminoacídicas (missense), codones de término temprano (nonsense), alteraciones del splicing, así como deleciones y duplicaciones ${ }^{8-10}$. Sin embargo, destaca la alta frecuencia en población europea y americana, de una deleción de $57 \mathrm{~kb}$ que abarca los 10 primeros exones del gen CTNS, causando nula expresión de la proteína. La frecuencia de esta variante alcanza a $50 \%$ en algunas poblaciones, probablemente debido a un efecto fundador en Alemania hace más de 1.000 años $^{4,11}$.

En este artículo se describe una paciente de 12 meses con sospecha de $\mathrm{CN}$, en la que se consideró realizar un estudio molecular de CTNS para confirmar diagnóstico, facilitar acceso a cisteamina y ofrecer asesoramiento genético a los padres.

\section{Caso clínico}

Lactante de sexo femenino, peso y talla de $\mathrm{RN}$ de $3.190 \mathrm{~kg}$ y $49 \mathrm{~cm}$, respectivamente, primera gestación de padres sanos no consanguíneos, sin antecedentes familiares de nefropatías, con embarazo y parto normales. En el control en policlínico destacaba curva de crecimiento aplanada entre los 4 y 11 meses. Exámenes a los 9 meses mostraban anemia con hematocrito de $26 \%$ y creatinina 0,9 $\mathrm{mg} / \mathrm{dl}$. A los 12 meses presentó fiebre intermitente, decaimiento y disminución de la diuresis. Nuevos exámenes mostraron hematocrito de $23 \%$, creatinina $3,2 \mathrm{mg} / \mathrm{dl}$, y sin foco infeccioso clínico. Fue derivada a la Unidad de Cuidados Intensivos Pediátricos (UCIP) en Hospital Exequiel González Cortés, al cual llegó normotensa, con acidosis metabólica, hemoglobina de 5,9 g/ $\mathrm{dL}$, deshidratación severa y poliuria. La ecografía renal no reveló alteraciones. Se compensó con transfusión sanguínea. Los valores de creatinine- mia disminuyeron hasta $0,9 \mathrm{mg} / \mathrm{dl}$, requiriendo bicarbonato hasta $10 \mathrm{mEq} / \mathrm{kg}$. Se detectó proteinuria y glucosuria. En su conjunto, los antecedentes mostraron una tubulopatía renal proximal y ERC etapa 4 con clearance estimado $25-30 \mathrm{ml} / \mathrm{min} / 1,73$, requiriendo potasio, fósforo, calcio y magnesio. Dado el comportamiento clínico y confirmación de aminoaciduria generalizada, se estableció diagnóstico de síndrome de Fanconi y continuó en tratamiento de ERC etapa 4. Se sospechó una causa primaria congénita y se decidió realizar estudio molecular del gen CTNS para precisar el diagnóstico y facilitar uso de cisteamina.

\section{Análisis genético de los exones 3-12 y deleción de $57 \mathrm{~kb}$ del gen CTNS}

Se solicitó a los padres la firma de consentimiento informado, aprobado por el Comité de Ética Científico del Servicio de Salud Valdivia. El ADN genómico del trío (padre/madre/probando) fue extraído de linfocitos de sangre periférica y analizado por PCR en los exones 3-12 (codificantes) del gen CTNS con perfil $95^{\circ} \mathrm{C} \times 3 \mathrm{~min} ; 35$ ciclos de $95^{\circ} \mathrm{C}$ x $1 \mathrm{~min}, 55^{\circ} \mathrm{C}$ x $1 \mathrm{~min}, 72^{\circ} \mathrm{C}$ x $1 \mathrm{~min} ; 72^{\circ}$ $\mathrm{C}$ x $5 \mathrm{~min}$. Además, se analizó la deleción de 57 $\mathrm{kb}$, mediante PCR específicas denominadas LDM (423pb) y del microsatélite D17S829 (266 pb) con perfil $94^{\circ} \mathrm{C} \times 15 \mathrm{~min}, 30$ ciclos de $94^{\circ} \mathrm{C}$ x $30 \mathrm{seg}$, $55^{\circ} \mathrm{C}$ x $40 \mathrm{seg}, 72^{\circ} \mathrm{C} \times 1 \mathrm{~min} ; 72^{\circ} \mathrm{C}$ x $10 \mathrm{~min}^{12}$. Los productos de PCR se sometieron a electroforesis en agaros a $2 \%$.

El ensayo de PCR de los exones 3-12 del gen CTNS demostró una amplificación correcta en las muestras del padre y madre del probando (Figura 1). Sin embargo, los exones 3-10 no fueron amplificados en el probando, por lo que se evaluó la presencia de la deleción de $57 \mathrm{~kb}$. Esta estrategia consiste en dos ensayos de PCR: la primera reacción contiene partidores externos de la deleción (LDM), mientras que la segunda reacción contiene partidores internos (D17S829). El análisis permitió identificar en la paciente la deleción de $57 \mathrm{~kb}$ en homocigosis. Adicionalmente, se confirmó que los padres de la paciente son portadores heterocigotos de la deleción (Figura 2).

\section{Evolución}

Con cisteamina (Cystagon ${ }^{\circledR}$ ), la paciente presentó una buena evolución clínica mejorando parcialmente la función renal estabilizándose en 
ERC etapa 3, logrando un manejo metabólico satisfactorio y recuperación de peso y talla. El seguimiento oftalmológico reveló a los 12 meses de diagnóstico, la presencia de cristales de cistina ocular, por lo que inició uso de colirio de cisteamina.

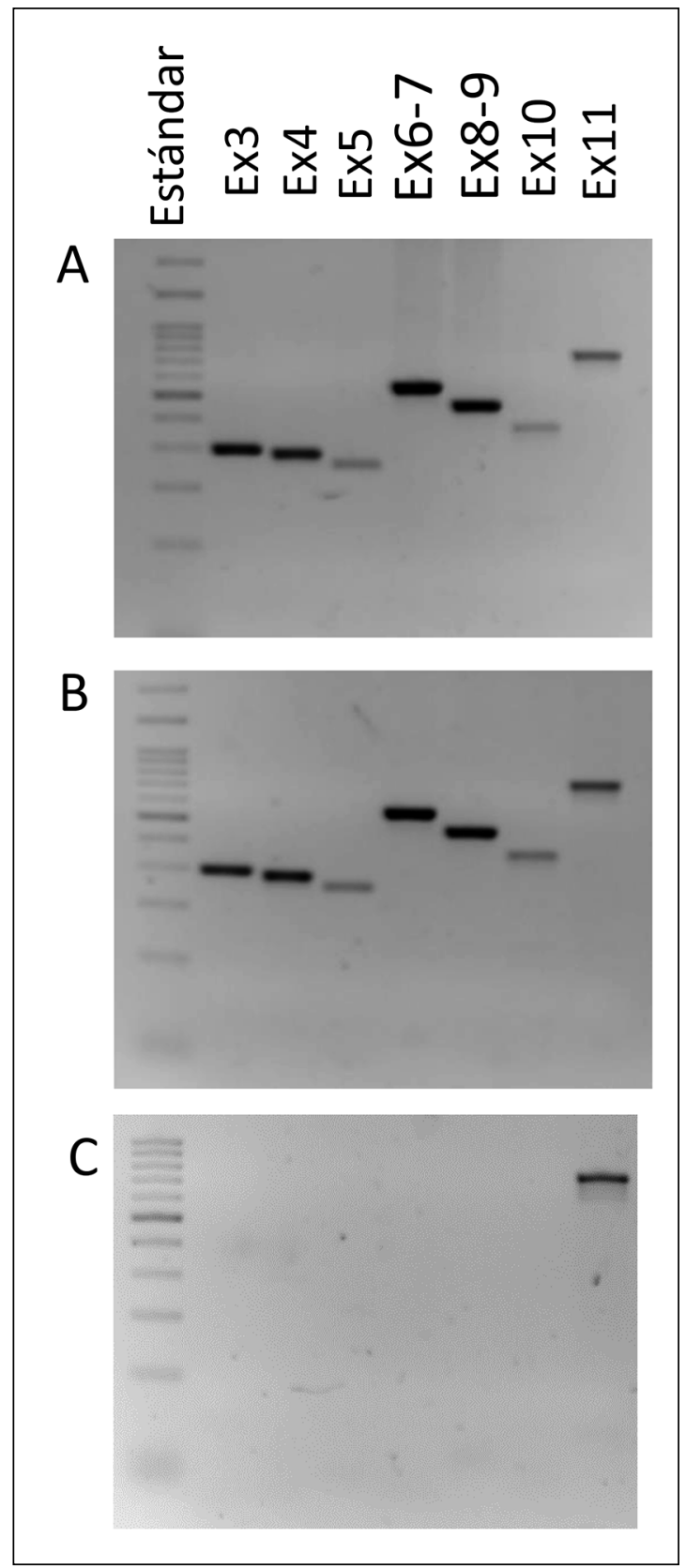

Figura 1. Amplificación por PCR de exones 3-12 de CTNS. Electroforesis en gel de agarosa de productos $P C R$ del padre (A), madre (B) y caso índice (C).

\section{Comentarios}

Este caso constituye el primer reporte de un paciente con sospecha clínica de $\mathrm{CN}$ que es confirmado mediante un estudio genético-molecular realizado en Chile. Si bien existen otros 3 casos de pacientes chilenos reportados, uno de ellos se confirmó mediante medición de cistina intracelular en el extranjero y no se dispone de información de estudios moleculares en los otros 2 casos $^{7,13}$.

La deleción de $57 \mathrm{~kb}$ es común en población europea, de la cual la población chilena es descendiente, pues el análisis de marcadores moleculares ha demostrado que posee $52 \%$ de composición genética de origen europeo ${ }^{14}$. Por lo tanto, resulta razonable priorizar el análisis de la deleción para diagnóstico molecular de $\mathrm{CN}$ en Chile. En Latinoamérica, la deleción ha sido identificada en 13/35 pacientes de Brasil y en 3/9 pacientes de México ${ }^{15,16}$.

La literatura destaca un análisis que comparó centros de países desarrollados (PD) y de países en vías de desarrollo (PVD), entre ellos Chile, y sugiere que las mayores discrepancias se encuentran en el manejo clínico de la CN: solo 54\% de los pacientes en $\mathrm{PVD}$ reciben el fármaco, presentando una evolución comparable a la de pacientes en PD hace 30 años $^{17}$. El análisis destaca la importancia de acceder al tratamiento antes de los 2,5 años, para lograr una significativa sobrevida de la función renal. Esto es posible aumentando los esfuerzos

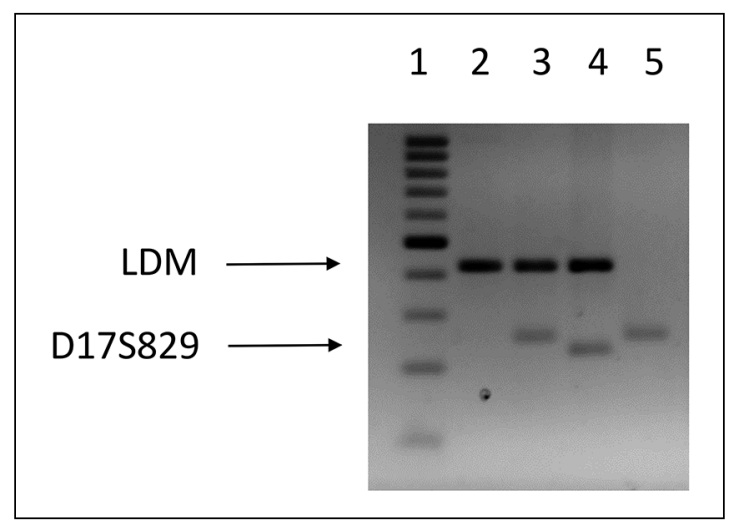

Figura 2. PCR específica de la deleción $57 \mathrm{~kb}$. Electroforesis en gel de agarosa de productos PCR para LDM y el microsatélite D17S829. En el carril 1: estándar de 100 pb (banda gruesa 500 pb); carril 2: caso índice; carril 3: padre; carril 4: madre; carril 5: individuo control (no pertenece al grupo familiar). 
para lograr una pesquisa y diagnóstico oportuno. Si bien existen dos métodos para diagnóstico de $\mathrm{CN}$, analítico y molecular, estos son realizados en el extranjero y el caso descrito en este artículo pretende destacar que es viable de implementar en Chile con un costo accesible.

\section{Consejo genético y diagnóstico prenatal}

La CN es una enfermedad muy rara, pero las parejas con antecedentes de hijos con diagnóstico o sospecha de $\mathrm{CN}$ debieran poder acceder a un estudio molecular de precisión para confirmar diagnóstico y tener asesoramiento genético, dado que el riesgo de recurrencia en una nueva gestación de padres heterocigotos es $25 \%$. Existe un número limitado de casos, inferior a $2 \%$, en que solo uno de los padres es portador de la mutación, que es heredada por el hijo afectado y el otro alelo presenta una mutación de novo, o bien el hijo afectado tiene una disomía uniparental del alelo afectado. En ambos casos, el riesgo de recurrencia disminuye a menos de $1 \%$.

Los síntomas de $\mathrm{CN}$ empiezan durante los primeros meses de vida y la posibilidad de realizar un diagnóstico temprano en etapa de $\mathrm{RN}$ permitiría un monitoreo y terapia sintomatológica más oportunos. Actualmente, si se conoce la alteración molecular subyacente, es posible realizar diagnóstico prenatal con vellosidades coriónicas o amniocentesis, así como diagnóstico preimplantacional.

\section{Manejo terapéutico}

La confirmación de este diagnóstico debiera acompañarse con el acceso universal y oportuno al tratamiento acorde a la sintomatología. En la actualidad, la cisteamina es el único fármaco disponible para el tratamiento de la CN. Además de la fórmula en cápsulas orales, se ha desarrollado el formato en colirio para contrarrestar la acumulación de cristales en la córnea y prevenir la fotofobia ${ }^{18}$. A nivel renal, el tratamiento con cisteamina ha demostrado retardar la progresión a ERC terminal y, cuando el paciente presenta un clearence de creatinina menor a $20 \mathrm{ml} / \mathrm{m} / 1,73 \mathrm{~m}^{2}$, es necesario considerar el trasplante renal. De acuerdo a la literatura, el trasplante con donante vivos, incluidos portadores heterocigotos, tiene buenos resultados, aunque se desarrollarán otras complicaciones multisistémicas ${ }^{19}$.

Existen diversas líneas de investigación que abren otras posibilidades de terapia en $\mathrm{CN}$, como modelos murinos de cistinosis que han respondido favorablemente al tratamiento con células madre modificadas genéticamente para reponer la cistinosina ${ }^{20}$. Asimismo, resulta esencial definir las bases fisiopatológicas de la CN, para identificar blancos específicos y disminuir o revertir el daño celular 5 .

\section{Referencias}

1. Town M, Jean G, Cherqui S, et al. A novel gene encoding an integral membrane protein is mutated in nephropathic cystinosis. Nat Genet 1998; 18(4): 319-24.

2. Gahl WA, Bashan N, Tietze F, Bernardini I, Schulman JD. Cystine transport is defective in isolated leukocyte lysosomes from patients with cystinosis. Science 1982; 217(4566): 1263-5.

3. Broyer M, Guillot M, Gubler MC, Habib R. Infantile cystinosis: a reappraisal of early and late symptoms. Adv Nephrol Necker Hosp 1981; 10: 137-66.

4. Gahl WA, Thoene JG, Schneider JA. Cystinosis. N Engl J Med 2002; 347(2): 111-21.

5. Wilmer MJ, Emma F, Levtchenko EN. The pathogenesis of cystinosis: mechanisms beyond cystine accumulation. AJP Ren Physiol 2010; 299(5): F905-F16.

6. Jézégou A, Llinares $\mathrm{E}$, Anne $\mathrm{C}$, et al. Heptahelical protein PQLC2 is a lysosomal cationic amino acid exporter underlying the action of cysteamine in cystinosis therapy. Proc Natl Acad Sci U S A 2012; 109(50): E3434-43.

7. Puentes RR, lbáñez TS, Solar GE, Valenzuela LA, Aracena AM. Cistinosis nefropática infantil. Rev Chil Pediatr 2000; 71(2): 122-7.

8. Phornphutkul C, Anikster Y, Huizing M, et al. The Promoter of a Lysosomal Membrane Transporter Gene, CTNS, Binds Sp-1, Shares Sequences with the Promoter of an Adjacent Gene, CARKL, and Causes Cystinosis If Mutated in a Critical Region. Am J Hum Genet 2001; 69(4): 712-21.

9. Kalatzis V, Cohen-Solal L, Cordier B, et al. Identification of 14 novelCTNS mutations and characterization of seven splice site mutations associated with cystinosis. Hum Mutat 2002; 20(6): 439-46.

10. Taranta A, Wilmer MJ, van den Heuvel LP, et al. Analysis of CTNS gene transcripts in nephropathic cystinosis. Pediatr Nephrol 2010; 25(7): 1263-7.

11. Shotelersuk V, Larson D, Anikster Y, et al. CTNS Mutations in an American-Based Population of Cystinosis Patients. Am J Hum Genet 1998; 63(5): 1352-62.

12. Anikster Y, Lucero C, Touchman JW, et al. Identification and detection of the common $65-\mathrm{kb}$ deletion 
breakpoint in the nephropathic cystinosis gene (CTNS). Mol Genet Metab 1999; 66(2): 111-6.

13. Bertholet-Thomas A, Berthiller J, Tasic V, et al. Worldwide view of nephropathic cystinosis: results from a survey from 30 countries. BMC Nephrol 2017; 18(1): 210.

14. Eyheramendy S, Martínez FI, Manevy F, Vial C, Repetto GM. Genetic structure characterization of Chileans reflects historical immigration patterns. Nat Commun $2015 ; 6: 6472$.

15. Alcántara-Ortigoza MÁ, Belmont-Martínez L, Vela-Amieva M, González-Del Angel A. Analysis of the CTNS Gene in Nephropathic Cystinosis Mexican Patients: Report of Four Novel Mutations and Identification of a False Positive 57-kb Deletion Genotype with LDM-2/Exon 4 Multiplex PCR Assay. Genet Test 2008; 12(3): 409-14.
16. Vaisbich MH, Koch VH. Report of a Brazilian multicenter study on nephropathic cystinosis. Nephron Clin Pract 2010; 114(1): c12-8.

17. Bertholet-Thomas A, Bacchetta J, Tasic V, Cochat P. Nephropathic cystinosis-a gap between developing and developed nations. N Engl J Med 2014; 370(14): 1366-7.

18. Gahl WA, Kuehl EM, Iwata F, Lindblad A, Kaiser-Kupfer MI. Corneal Crystals in Nephropathic Cystinosis: Natural History and Treatment with Cysteamine Eyedrops. Mol Genet Metab 2000; 71(1-2): 100-20.

19. Nesterova G, Gahl W. Nephropathic cystinosis: late complications of a multisystemic disease. Pediatr Nephrol 2008; 23(6): 863-78.

20. Cherqui S. Is genetic rescue of cystinosis an achievable treatment goal? Nephrol Dial Transplant 2014; 29(3): 522-8. 